\title{
Enhancement of Micro Turbine-Generator Output Voltage Quality through Application of Matrix Converter Interface
}

\author{
P.Raja Sekhar, L.Suresh \\ Assistant Professor Department of Electrical \& Electronics Engineering Sri Venkatesa Perumal College of \\ Engineering \& Technology, Puttur. \\ PG Student (PE\&Ed) Department of Electrical \& Electronics Engineering Sri Venkatesa Perumal \\ College of Engineering \& Technology, Puttur.
}

\begin{abstract}
Micro turbine-generator is suitable for different distributed generation applications. Due to its high speed, it is necessary to use a frequency converter to deliver the power at $50 / 60 \mathrm{~Hz}$. In this paper, application of Matrix Converter as micro turbine-generator interface converter is addressed. In this way, the interface converter becomes more compact due to omission of dc link capacitor (common in rectifier-inverter interface structure). Also, it is shown by the simulation results that by using matrix converter, quality of the output voltage is enhanced.
\end{abstract}

Keywords: Micro turbine-Generator (MTG), Matrix Converter (MC), Harmonics

\section{INTRODUCTION}

In recent years, application of Distributed Generation (DG) sources has increased significantly. Micro turbine- Generator (MTG) is well suitable for different distributed generation applications, because it can be connected in parallel to serve larger loads, can provide reliable power and has low-emission. MTGs have the rated power from 30 to $250 \mathrm{~kW}$, generating electricity in ac, and they can be installed in isolated conditions or synchronized with the electrical utility. The main characteristics of MTG can be summarized in low maintenance, capacity of operation with liquid and gas fuels (including natural gas) and small area required for installation [1]. MTGs are available as single-shaft or split-shaft units. Single-shaft unit is a high-speed synchronous machine with the compressor and turbine mounted on the same shaft. While, the split-shaft design uses a power turbine rotating at $3000 \mathrm{rpm}$ and a conventional generator connected via a gearbox for speed multiplication [2]. In this paper, the single-shaft structure is considered. Single-shaft MTGs are usually composed of gas turbines, electric power generators (usually a permanent magnet synchronous generatorPMSG), frequency converters (interface converters), and protection and control systems (Fig. 1) [1]. The interface converter is used to convert PMSG output voltage frequency (high frequency) to power system (50/60 $\mathrm{Hz}$ ) frequency.

\section{MICROTURBINE MODELING}

In this paper, the model proposed in $[3,4]$ is considered for micro turbine. The modeling of micro turbine has been done in Matlab/Simulink (Fig. 2). As can be seen in Fig. 2, the model is made up of speed controller, acceleration controller, temperature controller and fuel system (including valve positioned and actuator). The exhaust temperature function $f 1$ and torque function $f 2$ is given by:

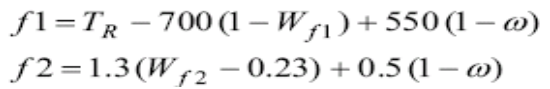

Where w denotes turbine speed, $W f 1$ and $W f 2$ are fuel flows signals, and $T R$ denotes rated exhaust temperature.

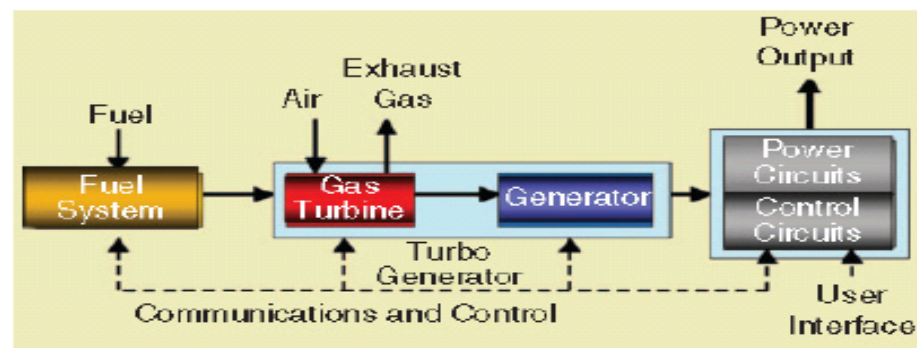

Fig. 1. Block diagram of a single-shaft MTG 


\section{MATRIX CONVERTER (MC)}

$\mathrm{MC}$ is an array of controlled semiconductor switches that connects directly the three-phase source to the three phase load. In the other words, MC performs a direct AC/AC conversion. While, AC/AC conversion is conventionally achieved by a rectifier stage, a dc link and an inverter stage. Since, in the MC the switching is performed on sinusoidal waveforms, the output voltage quality can be better than the conventional rectifier inverter structure. Also, there is no dc-link (large energy storage element) in MC. So, the MC is more compact compared to conventional AC/AC converters [5,6]. A common matrix converter structure consisting of $3 \times 3$ switches is shown in Fig. 3. As can be seen, it connects a three-phase voltage source to a three-phase load [6].

The matrix converter requires a bidirectional switch capable of blocking voltage and conducting current in both directions. Unfortunately, there are no such devices currently available, so discrete devices need to be used to construct suitable switch cells. In this paper, the common-emitter back to back structure is used as bidirectional switch. The Simulink model of this switch is shown in Fig. 4.

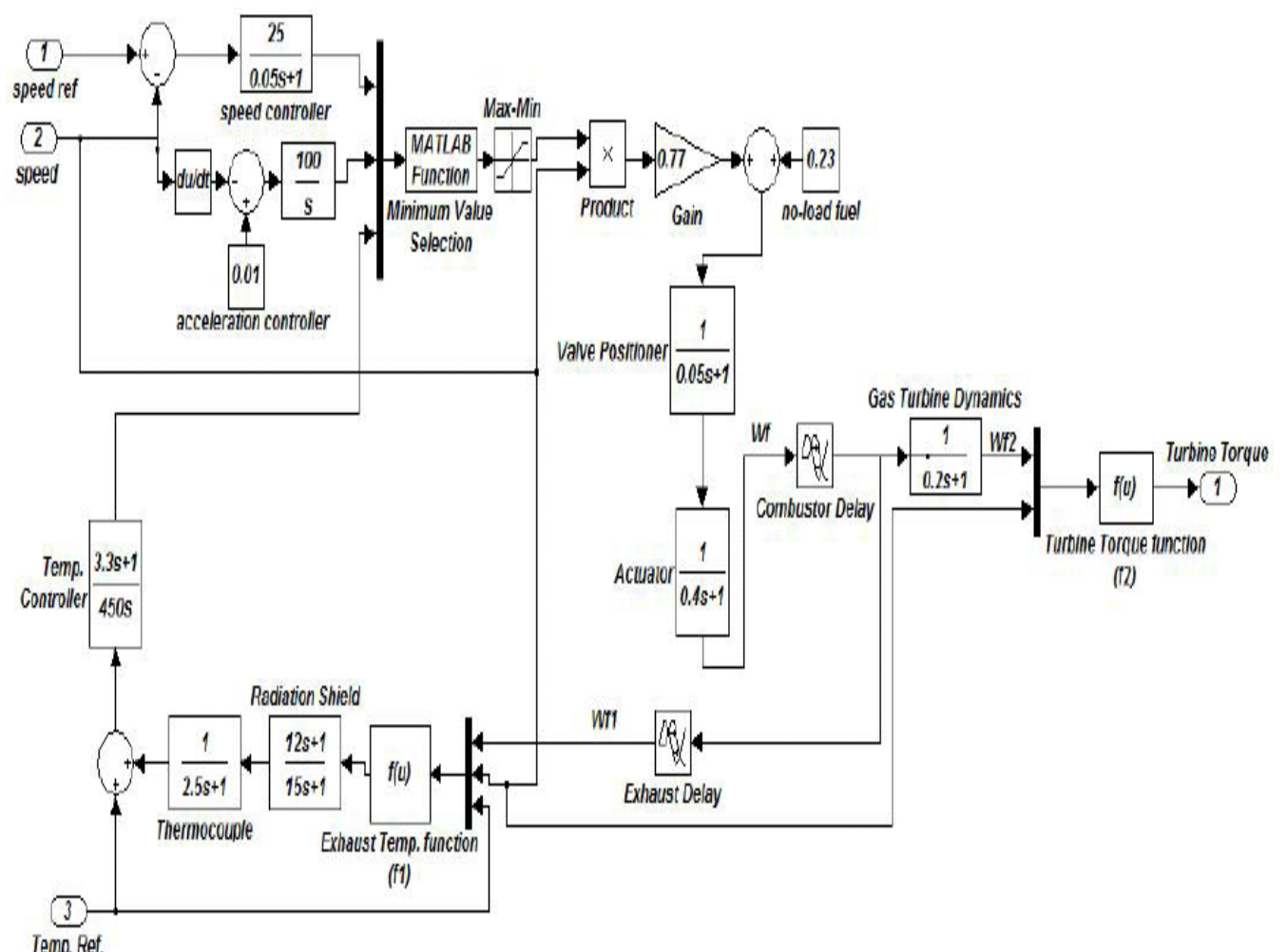

Fig. 2. Microturbine model

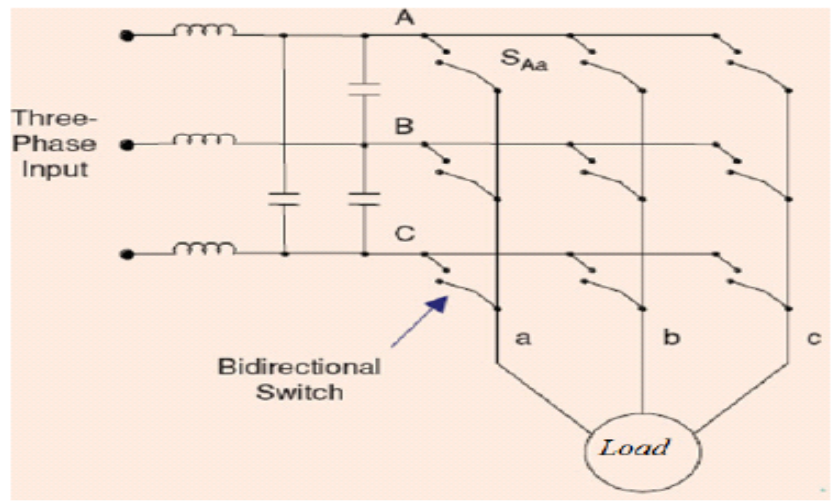

Fig. 3. Basic MC Structure

Normally, the matrix converter is fed by a voltage source and, for this reason; the input terminals should not be short circuited. On the other hand, the load has typically an inductive nature and, for this reason, an output phase must never be opened [5]. Considering Fig. 3 and de fining the switching function of a single switch as [5]: 
$S_{K j}= \begin{cases}1 & \text { switch } S_{K j} \text { closed } \\ 0, & \text { switch } S_{K j} \text { open }\end{cases}$

$K=\{A, B, C\} \quad j=\{a, b, c\}$

The constraints discussed above can be expressed by:

$S_{A j}+S_{B j}+S_{C j}=1, \quad j=\{a, b, c\}$

The load and source voltages of Fig. 3 with reference to supply neutral are considered as follows:

$V_{o}=\left[\begin{array}{l}v_{a}(t) \\ v_{b}(t) \\ v_{c}(t)\end{array}\right] \quad V_{i}=\left[\begin{array}{l}v_{A}(t) \\ v_{B}(t) \\ v_{C}(t)\end{array}\right]$

So, it can be written that:

$$
\begin{aligned}
& {\left[\begin{array}{l}
v_{a}(t) \\
v_{b}(t) \\
v_{c}(t)
\end{array}\right]=\left[\begin{array}{lll}
S_{A a}(t) & S_{B a}(t) & S_{C a}(t) \\
S_{A b}(t) & S_{B b}(t) & S_{C b}(t) \\
S_{A c}(t) & S_{B c}(t) & S_{C c}(t)
\end{array}\right]\left[\begin{array}{l}
v_{A}(t) \\
v_{B}(t) \\
v_{C}(t)
\end{array}\right]} \\
& V_{o}=T \cdot V_{i}
\end{aligned}
$$

Where $\mathrm{T}$ is the instantaneous transfer matrix. In order to derive modulation rules, it is also necessary to consider the switching pattern that is employed. This typically follows a form similar to that shown in Fig. 5.

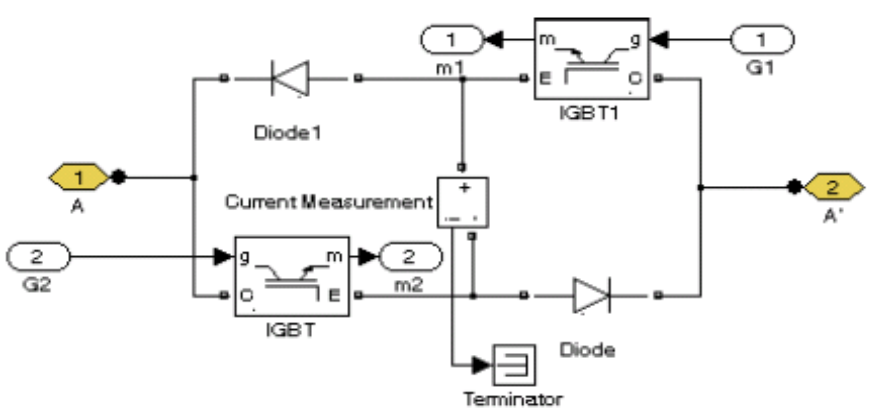

Fig. 4. Simulink model of bidirectional switch

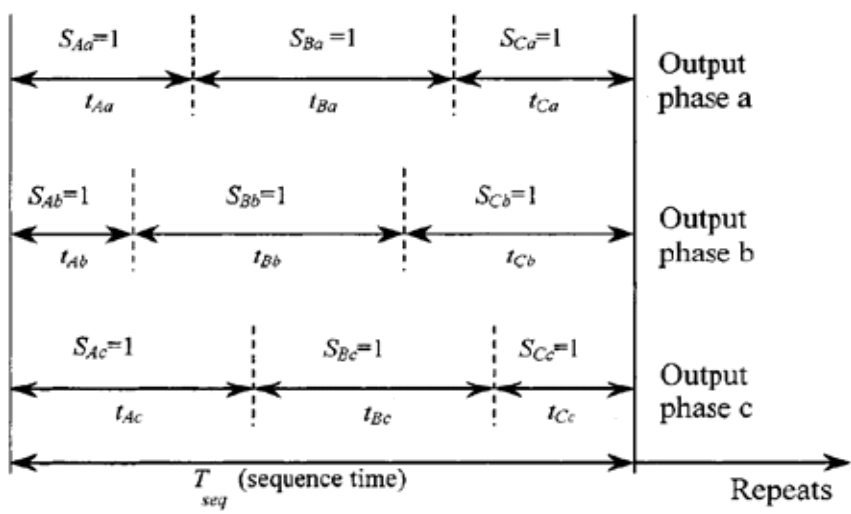

Fig.5. Switching pattern

By considering that the bidirectional power switches work with high switching frequency, a lowfrequency output voltage of variable amplitude and frequency can be generated by modulating the duty cycle of the switches using their respective switching functions. Let mkj(t) be the duty cycle of switch Skj, defined as $\operatorname{mkj}(\mathrm{t})=\mathrm{tkj} / \mathrm{Tseq}$, which can have the following values:

$0<m_{K j}<1 \quad K=\{A, B, C\} \quad j=\{a, b, c\}$

The low-frequency transfer matrix is defined by:

$$
M(t)=\left[\begin{array}{lll}
m_{A a}(t) & m_{B a}(t) & m_{C a}(t) \\
m_{A b}(t) & m_{B b}(t) & m_{C b}(t) \\
m_{A c}(t) & m_{B c}(t) & m_{C c}(t)
\end{array}\right]
$$


The low-frequency component of the output phase voltage is given by:

$$
\bar{V}_{o}(t)=M(t) V_{i}(t)
$$

Some modulation techniques have been presented for MC control. The most popular of them are Venturini, Scalar, and Space Vector Modulation (SVM) methods [5].

In this paper, the Venturini method is applied for MC control. In this method, switching timing can be expressed in terms of the input voltages and the target output voltages, as follows:

$$
\begin{gathered}
m_{K j}=\frac{t_{K j}}{T_{\text {seq }}}=\frac{1}{3}\left[1+\frac{2 v_{K} v_{j}}{V_{i m}^{2}}\right] \\
K=\{A, B, C\} \quad j=\{a, b, c\}
\end{gathered}
$$

Where, $i_{m} V$ is the amplitude of source voltages.

\section{PERMANENT MAGNET SYNCHRONOUS GENERATOR (PMSG)}

Micro turbine produces electrical power via a high-speed generator directly driven by he turbo compressor shaft. Small gas turbines benefit in particular when the gearbox that reduces the shaft speed to the speed of conventional electrical machines is eliminated, as is the case with the single-shaft designs considered here. The result is a more efficient, compact and reliable machine and the shaft speed is normally above 30,000 $\mathrm{rev} / \mathrm{min}$ and may exceed 100,000 rev/min. High energy permanent magnets and high yield-strength materials like neodymium-iron-boron $(\mathrm{NdBFe})$ or Samarium-cobalt magnets have proved very suitable for high-speed electrical machines .

In the following sections the equivalent circuit of a permanent magnet synchronous machine (PMSM) is presented along with a brief description of its construction, operation and the permanent magnet materials. In a permanent magnet synchronous machine, the dc field winding of the rotor is replaced by a permanent magnet. The advantages are elimination of filed copper loss, higher power density, lower rotor inertia, and more robust construction of the rotor. The drawbacks are loss of flexibility of field flux control and possible demagnetization. The machine has higher efficiency than an induction machine, but generally its cost is higher.

\section{PERMANENT MAGNET MATERIALS}

The property of a permanent magnet and the selection of the proper materials are very important in the design of a permanent magnet synchronous machine (PMSM). A good permanent magnet should produce a high magnetic field with a low mass, and should be stable against the influences which would demagnetize it. The desirable properties of such magnets are typically stated in terms of the remanence and coercivity of the materials, and are quoted in Tesla, the basic unit for magnetic field B.

Iron, nickel, cobalt and some of the rare earth metals exhibit a unique magnetic behavior which is called ferromagnetism. Ferromagnets tend to stay magnetized to some extent after being subjected to an external magnetic field. The fraction of the saturation magnetization retained (remanence) when the driving filed is removed is an important factor for the selection of the permanent magnets. All ferromagnetic materials have a maximum temperature known as Curie temperature, where the ferromagnetic property disappears. Consequently, the range of temperatures plays an important role in the operation of a PMSM.

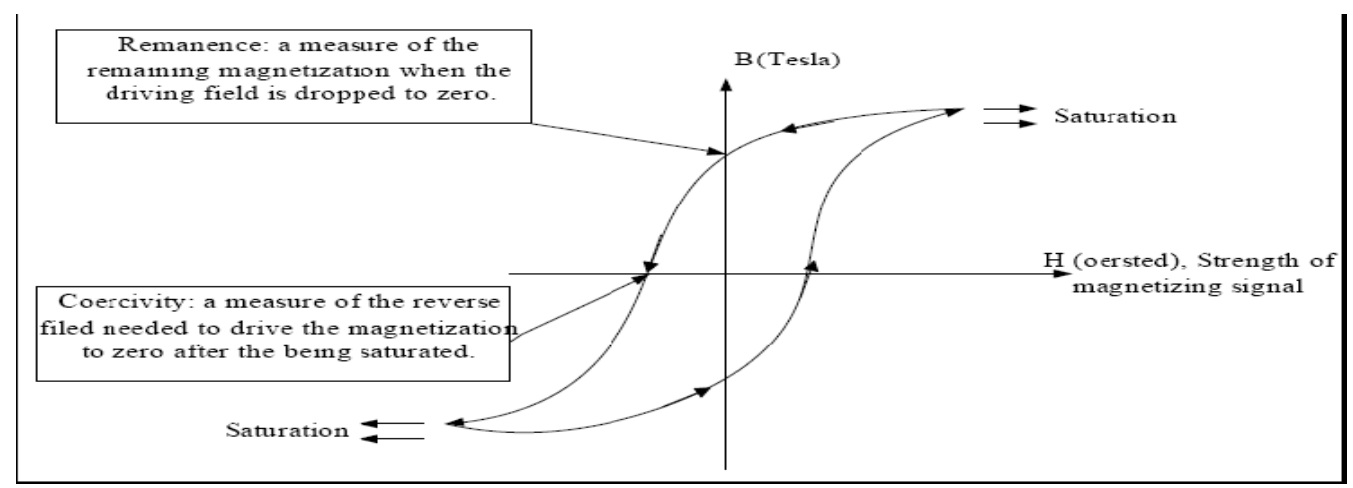

Fig. Hysteresis loop in the form of magnetization B and magnetic field strength $\mathrm{H}$.

\section{SIMULATION RESULTS}

In this section, the MTG is simulated in Matlab/Simulink. The model of PMSG available at Simulink library is used for generator simulation. This PMSG has 8 poles and its rated power is $30 \mathrm{~kW}$. In simulations, the 
focus will be on comparison of output voltage quality of two MTG interface converters (matrix converter and conventional rectifier-inverter structure). In order to perform a true comparison, switching frequency of both converters is set to $5 \mathrm{kHz}$ and output LC filters parameters are chosen to be the same. The block diagram of the simulated system is shown in Fig. 6.

The reference speed of the MTG is set to $45000 \mathrm{rpm}$. At first, The RLC load is $0.2 \mathrm{pu}$. Then, at $\mathrm{t}=14 \mathrm{sec}$, the load has a step increase to $0.8 \mathrm{pu}$. The torque response of the micro turbine is compared with the load demand in Fig. 7. It can be seen that the torque has a good convergence. Also, speed of MTG is shown in Fig.8. As it can be observed, the speed converges to its reference value, too.

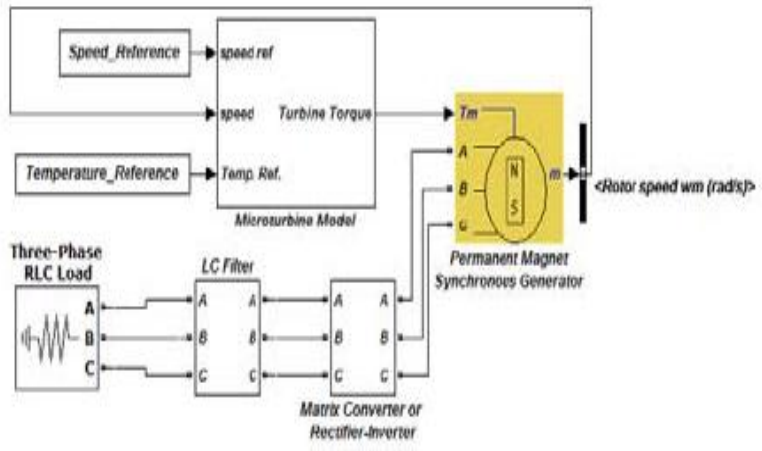

Fig.6. Simulated system

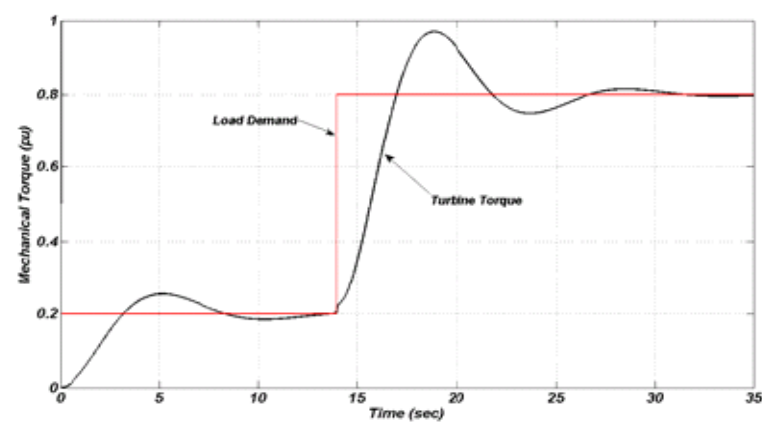

Fig.7. Mechanical Torque of MTG

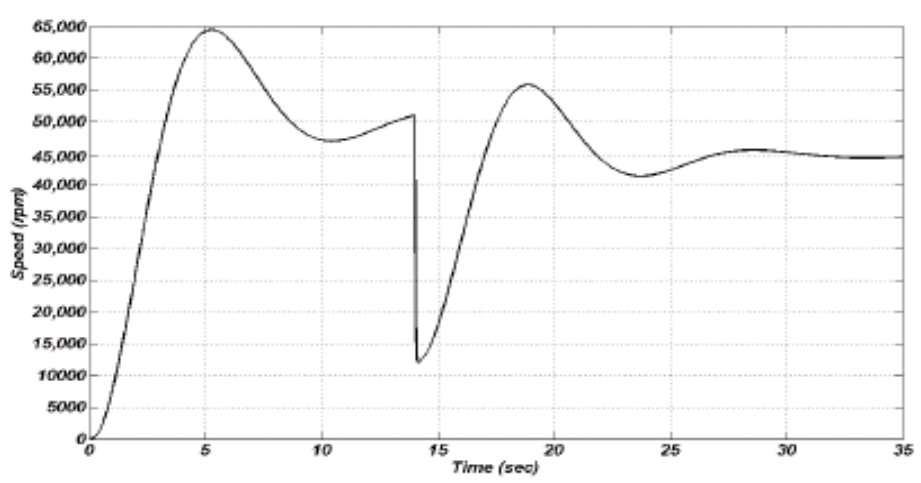

Fig.8. Speed of MTG

At this speed, the output frequency of the PMSG is $3000 \mathrm{~Hz}$ and must be converted to power system frequency $(60 \mathrm{~Hz})$. As it is mentioned earlier, it can be achieved using matrix converter or conventional rectifierinverter structure. In Figs 9(a) and 9(b), PMSG output phase-a voltages at $0.2 \mathrm{pu}$ and $0.8 \mathrm{pu}$ loads are shown.

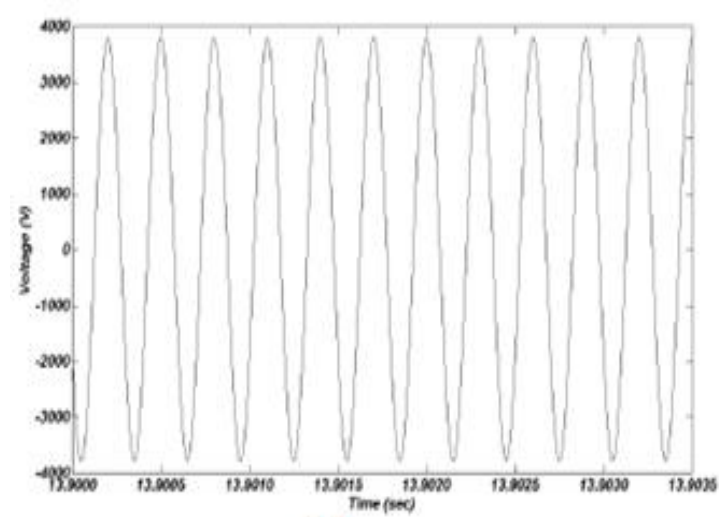

(a)

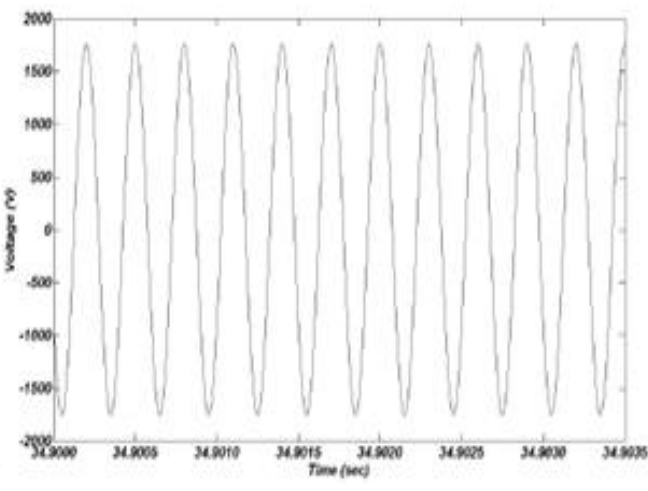

(b)

Fig.9. PMSG output voltage: (a) load $=0.2 \mathrm{pu}$ (b) load $=0.8 \mathrm{pu}$

Matrix and conventional converters operate on these load voltages to construct a $60 \mathrm{~Hz}, 440 \mathrm{~V}(\mathrm{p}-\mathrm{p})$ output voltage. Output waveforms of these converters before filtering are shown in Figs. 10 and 11, respectively. 

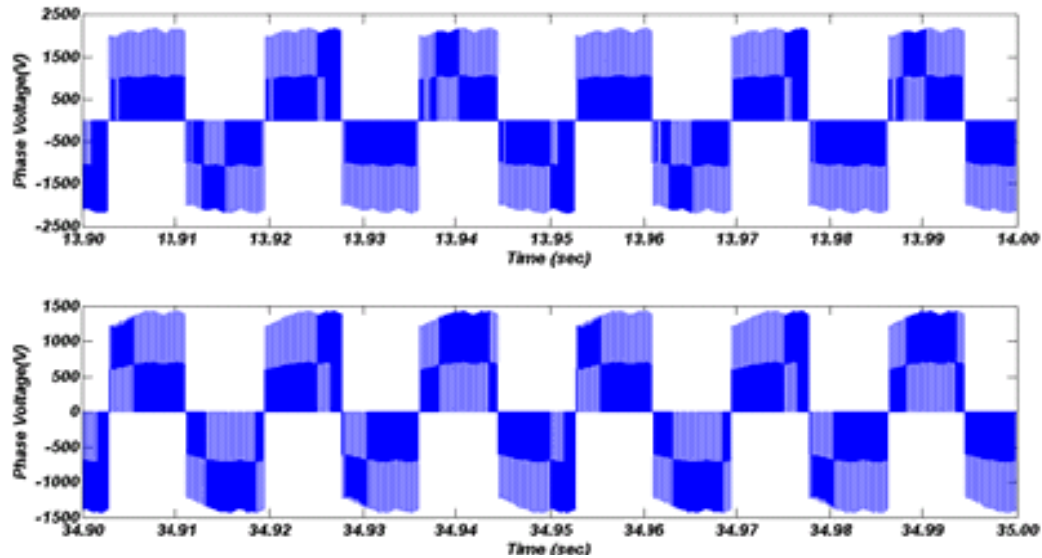

Fig.10. MC output voltage: load= $0.2 \mathrm{pu}$ (top) load=0.8 pu (bottom)
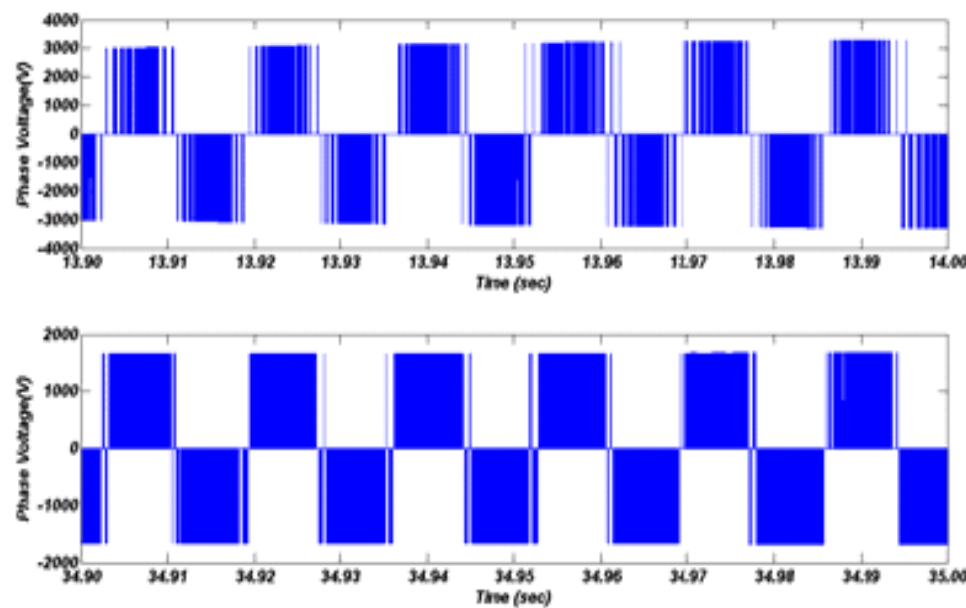

Fig.11. Conventional converter output voltage: load= $0.2 \mathrm{pu}$ (top) load=0.8 pu (bottom)

These voltages are filtered by the LC filter to construct the load terminal voltages. Figs 12 and 13 show the filtered voltages waveforms. As it can be seen, the voltage THD values $(5.5 \%$ and $4.5 \%$ for 0.2 and $0.8 \mathrm{pu}$ loads) using $\mathrm{MC}$ are less than the ones in the case of conventional rectifier-inverter structure $7.2 \%$ and $6.5 \%$ for 0.2 and 0.8 pu loads).
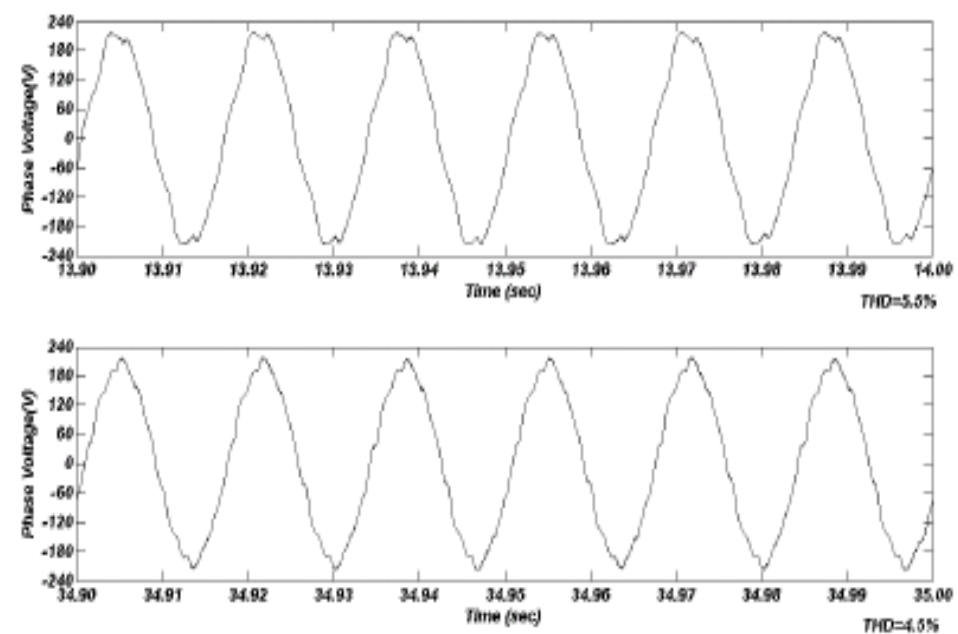

Fig.12. load terminal voltage using MC: load= $0.2 \mathrm{pu}$ (top) load=0.8pu (bottom) 

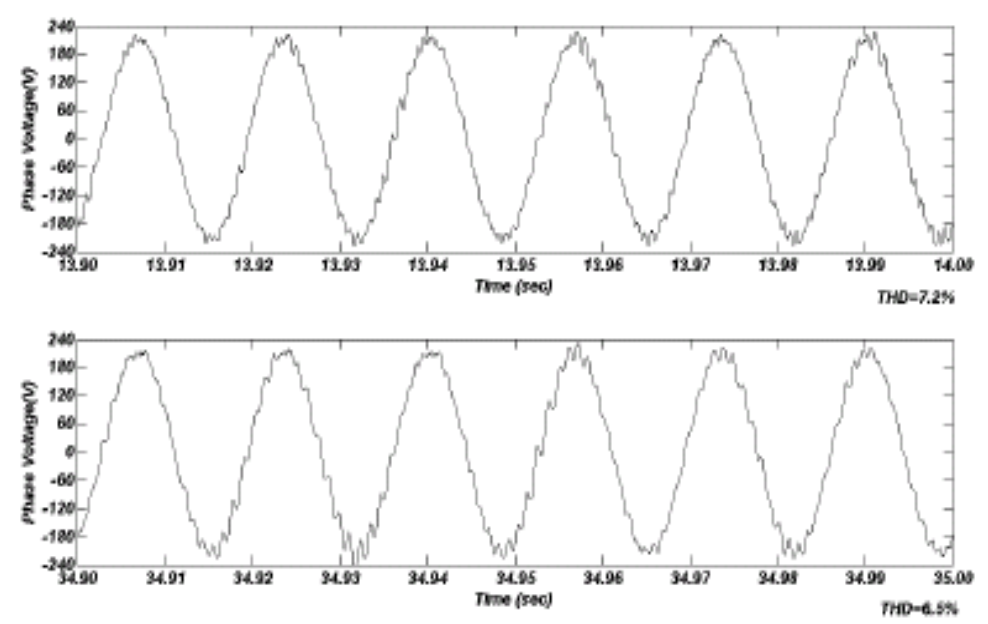

Fig.13. load terminal voltage using conventional converter: load $=0.2 \mathrm{pu}$ (top) load=0.8 pu (bottom)

\section{CONCLUSIONS}

In this paper, application of the matrix converter as output frequency converter in micro turbinegenerator is addressed. Comparison of simulation results of MTG using matrix and conventional interface converters demonstrated the ability of $\mathrm{MC}$ to deliver a higher quality voltage to the load.

Also, it is worthy to be noted that through application of MC the large dc link capacitor which is common in the rectifier-inverter structure is omitted. So, the interface converter can be more compact and less expensive.

\section{REFERENCES}

[1]. E. F. Pavinatto, M. B. Peres, P. D. Reis, L. S. Pereira, and F. P. Salles, "Use of micro turbines in remote isolated oil and gas facilities in Brazil", IEEE Ind. Appl. Mag., pp. 62-68, Nov./Dec. 2008.

[2]. A. K. Saha, S. Chowdhury, S. P. Chowdhury, and P. A. Crossley, "Modeling and performance analysis of a Micro turbine as a distributed energy resource”, IEEE Trans. Energy Conv., vol. 24, no. 2, pp. 529-538, Jun. 2009.

[3]. T. Yu, J. Tong, and K. W. Chan, "Study on micro turbine as a back-up power supply for power grid black-start", IEEE Int. Conf. 2009.

[4]. R. Noroozian, M. Abedi, G. B. Gharehpetian, and S. H. Hosseini, "Modelling and simulation of micro turbine generation system for on-grid and off-grid operation modes”, Int.1 Conf. on Renewable Energies and Power Quality (ICREPQ’09), Apr. 2009.

[5]. P. W. Wheeler, J. Rodriguez, J. C. Clare, L. Empringham, and A. Weinstein, "Matrix Converters: A Technology Review", IEEE Trans. Ind. Elec., vol. 49, no. 2, pp. 276-288, Apr. 2002.

[6]. P. W. Wheeler, J. C. Clare, L. Empringham, M. Bland, and K. G. Kerris, "A vector-controlled MCT matrix converter induction motor drive with minimized commutation time and enhanced waveform quality”, IEEE Ind. Appl. Mag., pp. 59-65, Jan./Feb. 2004.

\section{AUTHORS}

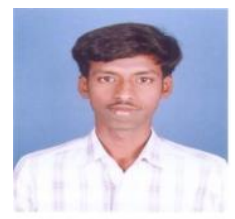

Mr.P.Raja sekhar born in Tirupathi in the year of 1986. His date of birth is 01.06.1986. He Completed hisB.Techin2008from SVPCET Puttur, Affiliated to JNTUA, Anantapur. He completed his M.Tech in 2011 from SITAMS Chittoor, Affiliated To JNTUA, Anantapur. $\mathrm{He}$ has 2years of teaching experience in various institutions. He is currently working as an Assistant Professor in the Department of EEE in SVPCET, Puttur.

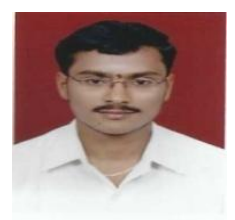

Mr.L.Suresh born in Tiruchanoor near to Tirupathi in the year of 1987. His date of birth is 15.07.1987. He completed his B.Tech in 2009 from SIETK, Puttur Affiliated to JNTUA, Anantapur. He has 3years of teaching experience in various institutions. He is currently persuing his M.Tech in SVPCET Puttur, Affiliated to JNTUA, Anantapur. 